Published in Philosophical Magazine Letters 86, 2006, 243-252

\title{
Reply to the Comments on "Room-temperature precipitation in quenched Al-Cu-Mg alloys: a model for the reaction kinetics and yield-strength development.”
}

\author{
M. J. Starink $\dagger^{*}$, A. Cerezoł, J.L. Yan†, N. Gao† \\ †Materials Research Group, School of Engineering Sciences, University of Southampton, Southampton, \\ SO17 1BJ, United Kingdom \\ $\ddagger$ Department of Materials, University of Oxford, Parks Road, Oxford OX1 3PH, United Kingdom
}

\begin{abstract}
Our recent work on $\mathrm{Al}-\mathrm{Cu}-\mathrm{Mg}$ - based alloys with $\mathrm{Cu}: \mathrm{Mg}$ ratio close to unity showed that the rapid hardening at room temperature and the substantial heat evolution arise from the formation of $\mathrm{Cu}-\mathrm{Mg}$ co-clusters. Here, it is shown that the measured enthalpy of formation of clusters $(\sim 0.3 \mathrm{eV}$ per $\mathrm{Mg}$ atom) is in reasonable agreement with expectations based on the similarity with Mg-vacancy clusters. The origin of the term GPB zones, as applied to the rapid hardening in Al-Cu-Mg - based alloys, is investigated. It is shown that current knowledge on the nanostucture and microstructure development during rapid hardening can be described without recourse to this alloy-specific term. Analysis of the kinetics of $\mathrm{Cu}-\mathrm{Mg}$ co-cluster formation by DSC indicates that the formation of $\mathrm{Cu}-$ $\mathrm{Mg}$ co-clusters during a fast water quench can be sufficiently suppressed to cause substantial nucleation of co-clusters to occur in subsequent natural ageing and artificial ageing at low temperatures.
\end{abstract}

In this reply to [1], which contains some comments on our paper [2], we would like to discuss a number of issues pertinent to points raised by Zahra et al. in the course of their paper. Before we deal with these we first want to note that much of [1] is taken up by a literature review and by a review of calorimetry data, which do not contradict our work. We will not comment on this but we do need to stress that the final interpretation by Zahra et al. [1] "[..] plate-like GPB zones which nucleate on clusters of irregular shape are responsible for the first hardening stage" is inconsistent with our three-dimensional atom probe (3DAP), differential scanning calorimetry (DSC) and hardness data on the two alloys we studied (Al-1.2Cu-1.2Mg and the Al-1.9Cu-1.6Mg (at\%)): our 3DAP data shows that neither of these alloys contain substantial numbers of platelet or rod-like structures such as GPB zones during several days ageing at room temperature, whilst the hardness increase and heat evolution is completed within about one day. We will show that all the data and theoretical considerations expressed in [1], as well as data in papers cited in [1], are fully consistent with our conclusions. Specifically we need to note that nowhere in [1], or in any of the papers cited therein, is any nano/microstructural data presented that show platelet or rod-shaped GPB zones within $\mathrm{Al}-\mathrm{Cu}-\mathrm{Mg}$ alloy samples with compositions and heat treatments near the ones we have studied. We believe that there is no conclusive microstructural data having the necessary resolution on $\mathrm{Al}-\mathrm{Cu}-\mathrm{Mg}$ alloys with both $\mathrm{Cu}$ and $\mathrm{Mg}$ contents in excess of $1 \mathrm{at} \%$, heat treated to times up to $5 \times$

\footnotetext{
* Corresponding author: Tel: 023 80595094; Fax: 023 80593016; Email:M.J.Starink@soton.ac.uk
} 
the time to complete the rapid hardening that actually shows anything like the GPB zones claimed by Zahra et al. [1].

We also note that our alloys in [2] have compositions that are different from the Al-Cu-Mg alloys that Zahra and co-workers have worked on through the years: our alloys all have a $\mathrm{Cu}: \mathrm{Mg}$ ratio close to 1 , a $\mathrm{Cu}$ content in excess of $1 \mathrm{at} \%$ and contain $0.2 \mathrm{at} \% \mathrm{Mn}$ and $0.1 \mathrm{at} \% \mathrm{Si}$ (similar to commercial 2024 / 2124 alloys). The five alloys for which calorimetry data is shown in [1] either have a much lower $\mathrm{Cu}: \mathrm{Mg}$ ratio (alloys $\mathrm{X}, \mathrm{Y}$ and $\mathrm{Z}$ ), or contain much less or no $\mathrm{Mn}$ or Si. We would stress that for our alloys the main exothermic effect in DSC below $200^{\circ} \mathrm{C}$ disappears during ageing for a few days at room temperature, whilst for the $\mathrm{Al}-0.25 \% \mathrm{Cu}-4.7 \% \mathrm{Mg}$ alloy (alloy $\mathrm{X}$ ) in [1] the exothermic effect remains present even after 3 months of room-temperature ageing (Fig. 2 in [1]). Owing to the large difference in composition and rate of the main low-temperature reaction, and in the absence of microstructural analysis (TEM, APFIM) on alloy X, we cannot presume that the structures formed in alloy X would be the same as that formed in our alloys. Mn and Si at the levels present in our alloys might cause some differences with the two higher purity ternary alloys with $\mathrm{Cu}: \mathrm{Mg}$ ratio close to 1 in [1], and some caution is required in comparing these results. Whilst composition differences are a source for caution, we will below follow the implied suggestion in [1] that they do not substantially alter early precipitation and aim to show that the issues highlighted in [1] do not contradict our findings. In addressing the issues raised in [1], we will first briefly consider just what evidence is available in the literature for the presence and nature of the structures often referred to as "GPB zones" and Cu-Mg co-clusters. Secondly, we will discuss heat evolution caused by clusters/zones as measured by calorimetry and consider whether this can give indications of the nature, volume fraction and composition of the pre-precipitates. Thirdly, we will consider the issue of possible nuclei for $\mathrm{Cu}-\mathrm{Mg}$ co-clusters present immediately after quenching. Finally, we will propose a rationalization of the literature data on $\mathrm{Al}-\mathrm{Cu}-\mathrm{Mg}$ alloys.

\section{What the literature says and does not say on "GPB zones"}

As is briefly noted by Zahra et al. [1], there are differences in interpretation in the literature on the nature of the structures responsible for early ageing. To provide a proper balance to the overview presented in [1] we would note here that opposing views are presented in $[3,4,5,6,7]$ and the review papers $[8,9]$, and several references therein. For a detailed overview of the literature we refer to these papers, and in the present paper we would like to present a more generic overview to evaluate the context in which the term and proposed definitions of "GPB zones" originated and our opinion concerning usage of this term.

The use of Al-Cu based alloys that were hardened by nanosized structures goes back at least to 1903 (in the engine that powered the historic Wright brothers flight [10]). The process of age-hardening in Al-Cu based alloys was first discovered in 1909 by Wilm (and published in 1911 [11]) and as early as 1919 the hardening was proposed to arise from clusters of atoms or precipitates [12]. To elucidate the (perceived) meaning of the term "GP(B) zones" we need to go back to the late 1930s when Guinier [13] and Preston [14] independently observed that, after low-temperature age hardening of quenched $\mathrm{Al}-\mathrm{Cu}$ based alloys (without $\mathrm{Mg}$ ), the hardened samples show additional effects in X-ray small-angle scattering diagrams, indicating that a structure is formed from the solid solution. Although the data obtained cannot provide evidence of composition or full structure, both Guinier and Preston provided an interpretation that is very close to what we know today: they 
ascribed the diffraction effects to platelets of $\mathrm{Cu}$ on (100) planes. (In fact, as Guinier later stated [15], identifying platelets of $\mathrm{Cu}$ on (100) planes as the source of the diffraction effects in $\mathrm{Al}-\mathrm{Cu}$ alloys is easy, but for other alloys that are age-hardened at or near room temperature, X-ray smallangle scattering data is ambiguous.) Soon, the structures were named after them: Guinier-Preston (GP) zones [15]. It wasn't until the 1980s and 1990s that, through application of the new techniques of atom probe field-ion microscopy (APFIM) and high-resolution electron microscopy (HREM), firm proof of their composition and crystallography was obtained. As was argued recently [8], the term GP zones for Al-Cu based alloys has now become rather obsolete, as the plates enriched in $\mathrm{Cu}$ can be thought of as a thin section of the $\theta^{\prime \prime}\left(\mathrm{Al}_{3} \mathrm{Cu}\right)$ phase.

In the late 1950s it was clear to researchers working on $\mathrm{Al}-\mathrm{Cu}-\mathrm{Mg}$ based that these ternary alloys also showed a rapid hardening reaction, and XRD data showed that the structures formed were different from that in Al-Cu alloys. The term "GPB zones" ( $\mathrm{B}$ is considered to stand for Bagaryatski, the author of an influential paper on the subject [16]) became associated with these structures, but none of the suggestions made in the 1950s or 1960s concerning their composition or crystallographic structure has been accepted, and (as stated in [17]) "understanding of the nature of such zones remained poor". Nonetheless, various researchers have attempted to provide a definition of what a "GPB zone" constitutes. Various researchers have suggested that a structure termed "GP(B) zones" can be distinguished from clusters or metastable ordered phases based on "GP(B) zones" having a specific combination of shapes, sizes, formation on certain crystallographic planes and degree of order [1]. We would note here that the gathering of characteristics that would together define a term that is specific to one single alloy system (or a limited few) is not actually progressing our understanding of the structures formed: only properly analysed experimental data, preferably with direct observation, can clarify which structures form in the first stage of ageing. It can be argued that the term "GPB zone" itself is superfluous, as its perceived meaning can be expressed with better defined, more general scientific terminology (not limited to metallurgy of precipitation hardening alloys) such as cluster, phase, ordered and metastable. For instance, if a "GPB zone" would be ordered, then it is more properly referred to as a metastable phase, and it can be termed a (small, nanometer-sized) metastable fully coherent precipitate. If it is not ordered we can call it a (small or large) cluster of atoms. The shape of the structure has little to do with the choice of terminology, we could refer for instance to an elongated cluster of atoms. It can be argued that the introduction of the term "GPB zone", and subsequent attempts to assign a meaning to it, has been responsible for substantial confusion in the literature in which terms like "ordered GPB zone", "GPB2 zone" or S" are now used interchangeably $[18,19,20]$. We would argue that in most of the pre-1995 literature and a substantial part of the post-1995 literature the use of the term GPB zone is best interpreted as meaning "unknown, unresolved hardening precipitate or cluster". Where rodshaped structures termed "GPB zones" were resolved (e.g. in early TEM work) this is best interpreted as "(rod-shaped) precipitate phase of unknown structure and unknown composition"; it is probable that many of these early observations relate to the orthorhombic, space group Cmmm, or the orthorhombic, space group Imm2 rod-shaped precipitate phases identified in $[18,19]$.

\section{The heat evolution due to $\mathrm{Cu}-\mathrm{Mg}$ co-clusters}

If we neglect minor sources of free energy (such as strain energy and interfacial energy), the total heat evolved in a reaction is the product of the enthalpy of formation (per mole clusters) and the 
amount formed [21]. The heat evolution observed during the effect we identified as $\mathrm{Cu}-\mathrm{Mg}$ cocluster formation [2] is substantial, about $14 \mathrm{~J} / \mathrm{g}$ for $\mathrm{Al}-1.9 \mathrm{Cu}-1.6 \mathrm{Mg}$ (at $\%$ ) samples analysed by DSC within 3 min of completing a solution treatment and quench, which is an order of magnitude larger than the value Zahra et al. [1] suggest as being typical for clusters. However, our data in [2] is very clear and consistent, and should in itself be sufficient evidence. In this reply we will provide several further reasonings to show that the heat effect we measured is in agreement with our interpretations of it, as well as relevant published data. In this section we will aim to firstly show that the works $[22,23,24,25]$ cited in [1], although valuable in their own right, actually do not give any reliable indication on the enthalpy of formation of $\mathrm{Cu}-\mathrm{Mg}$ co-clusters (per mole clusters) in $\mathrm{Al}$ based alloys. We derive this opinion from the following observations:

(i) Ref. [22] considers $\mathrm{Cu}$ clusters forming in amorphous alloys with compositions around $\mathrm{Fe}_{75} \mathrm{Si}_{12} \mathrm{~B}_{10} \mathrm{Nb}_{2} \mathrm{Cu}_{1}$ which is incomparable with our crystalline Al-based alloys, (clustering in an amorphous alloy may well have a lower enthalpy of formation (per mole clusters) as compared to clustering in a crystalline alloy);

(ii) Refs. $[23,25]$ consider heat effects proposed to be due to cluster formation in Al-Cu alloys with very low $\mathrm{Mg}$ additions (0.3at\%) and $\mathrm{Cu}: \mathrm{Mg}>6$ [23] or no $\mathrm{Mg}$ additions [25], and they cannot provide any information of the heat effect due to $\mathrm{Cu}-\mathrm{Mg}$ co-clusters, or any other preprecipitates in our alloys which have $\mathrm{Mg}$ contents between, 1 and $2 \mathrm{at} \%$ and $\mathrm{Cu}: \mathrm{Mg} \approx 1$;

(iii) Ref. [24] considers heat effects proposed to be due to "GPB-zones" and $\mathrm{Mg}$ cluster in $\mathrm{Al}-\mathrm{Cu}$ alloys with $\mathrm{Mg}: \mathrm{Cu}$ ratios ranging from 8 to 20. These alloys do not show a rapid hardening effect of the type observed in our alloys with $\mathrm{Mg}: \mathrm{Cu} \approx 1$, and they cannot provide any information of the heat effect due to $\mathrm{Cu}-\mathrm{Mg}$ co-clusters in our alloys;

(iv) Refs. [23,24,25] consider heat effects of reactions in which clusters of one type of atoms $(\mathrm{Cu}$ clusters or Mg clusters) are forming, which should be very different to the co-clusters forming in our alloys;

(v) Refs. $[1,23,24,25]$ do not contain any experimental data that identifies cluster formation in the alloys studied (by TEM, HREM, APFIM, or other technique that might be able to image them), and thus suggestions on the magnitude of any heat effects due to cluster formation remain unproven. These works do contain further references to early works that have used the term "GPB zones". We checked several but could not find any data that would contradict our views in [2]. (For instance where [23] states "The phases formed are also known from previous TEM observations (Chester and Polmear 1981); after GPB zone and $\theta$ " formation via GP zones the $\Omega$ phase precipitates rapidly at $\mathrm{Mg}-\mathrm{Ag}$ co-clusters", and where [1] states "Vietz and Polmear presented experimental data which support a $\mathrm{Cu}: \mathrm{Mg}$ ratio of about 1:1 for GPB zones" we would note that analysis of these two influential papers shows that they do not contain any proof that contradicts our findings in [2]. Similar conclusions can be derived from studying other pre-1990 papers.)

(vi) It seems that the only section in [23] linking evidence of cluster formation to heat contents of the reaction is: "It is interesting to note that the heat evolved in this case during the first 4 days (less than $1 \mathrm{~J} / \mathrm{g}$ ) is much less than for the same alloy aged directly after quenching (about 8.5 $\mathrm{J} / \mathrm{g}$ at RT according to DSC studies [..]. This suggests that, owing to the lack of vacancies, only cluster growth (rather than GP zone formation from Cu-rich clusters (Perry 1966)) occurs when the reverted alloy is aged around RT." We cannot see how this discussion referring to 
calorimetry data and 1960s (pre APFIM and pre HREM) work on Al-Cu alloys (with very low $\mathrm{Mg}$ additions $(<0.3 \mathrm{at} \%)$ and $\mathrm{Cu}: \mathrm{Mg}>6)$ supports the assertion that the heat content of formation of $\mathrm{Cu}-\mathrm{Mg}$ co-clusters in our $\mathrm{Al}-\mathrm{Cu}-\mathrm{Mg}$ alloys should be about $1 \mathrm{~J} / \mathrm{g}$.

In our opinion there is no proof that $\mathrm{Cu}-\mathrm{Mg}$ co-cluster formation should have an enthalpy of formation (per mole clusters) comparable to the low-temperature reactions in [22,23,24,25].

Our second point here is that the formation of clusters and co-clusters will have enthalpies of formation that will vary substantially with the type of atoms involved [26]. Experimental evidence can be found in the fact that binding energies of atoms with vacancies can vary at least an order of magnitude, depending on the type of alloying element involved [27]. The size of the atom(s) involved is an important factor [28], and thus $\mathrm{Mg}$ atoms (which increase the lattice parameter when dissolved in $\mathrm{Al}$ [29]) have a relatively high binding energy with vacancies (which decrease the lattice parameter of $\mathrm{Al}$ ), whilst $\mathrm{Cu}$ and $\mathrm{Si}$ (which decrease the lattice parameter when dissolved in $\mathrm{Al}$ $[29,30])$ have a relatively low binding energy. This size consideration indicates that the enthalpy for formation of $\mathrm{Cu}-\mathrm{Mg}$ co-clusters will be much higher than that of $\mathrm{Mg}-\mathrm{Mg}, \mathrm{Cu}-\mathrm{Cu}$ and Si-Si clusters and recent work supports this [31]. Thus, the experimental evidence in [1,2,22,23,24,25] is best interpreted to indicate that the product of enthalpy of formation (per mole clusters) and the amount of $\mathrm{Cu}-\mathrm{Mg}$ co-clusters formed in our $\mathrm{Al}-\mathrm{Cu}-\mathrm{Mg}$ alloys is quite simply larger than the cluster formation reactions observed in [22], or proposed to occur in [23,24,25]. Thus, there is no contradiction between the calorimetry data in [1,22,23,24,25] and our findings that the heat evolution observed during the $\mathrm{Cu}-\mathrm{Mg}$ co-cluster formation in our alloys [2] is about $14 \mathrm{~J} / \mathrm{g}$.

To provide an alternative estimate of the magnitude of the heat effect we propose the following semi-quantitative comparisons. Estimates based on a regular solution model outlined in [32], indicate that about $90 \%$ of the $\mathrm{Mg}$ present in the $\mathrm{Al}-1.9 \mathrm{Cu}-1.6 \mathrm{Mg}$ alloy can precipitate as $\mathrm{Cu}-\mathrm{Mg}$ co-clusters during a DSC run ${ }^{1}$. Then the enthalpy of formation in the Al-1.9Cu-1.6Mg alloy is $14 \mathrm{~J} / \mathrm{g}$ $\times 27.5 \mathrm{~g} / \mathrm{mol} /(0.016 \times 0.9)=0.27 \mathrm{eV}$ per $\mathrm{Mg}$ atom $^{2}$. We believe this enthalpy of formation will be determined to a large extent by the binding energy between $\mathrm{Mg}$ and $\mathrm{Cu}$, which in turn should be of comparable in magnitude to the binding energy between a $\mathrm{Mg}$ atom and a vacancy, which has been cited as $0.33 \mathrm{eV}[33,34]$ (also slightly lower values have been cited [35,36,37]). (Thus, in this simplified view, the main reason for heat release during co-cluster formation is proposed to be that each $\mathrm{Mg}$ atom initially surrounded by $\mathrm{Al}$ atoms forms a $\mathrm{Mg}-\mathrm{Cu}$ bond; and further heat release due to a $\mathrm{Mg}$ atom forming a second bond (with $\mathrm{Cu}$ or possibly a vacancy) is very limited.) The binding energy between a $\mathrm{Mg}$ atom and a vacancy $(0.33 \mathrm{eV})$ is similar to the enthalpy of formation of $\mathrm{Cu}-$ $\mathrm{Mg}$ co-clusters as measured by us $(\sim 0.27 \mathrm{eV})$, suggesting that the heat content of the effect ascribed

\footnotetext{
${ }^{1}$ It is noted that in 3DAP only the larger co-clusters are detected (the limit of 6-7 atoms in the reconstruction used in [2] means that due to the 50\% overall detection efficiency clusters with of minimum of 12-14 are detected). Thus APFIM cannot provide data on the amount of $\mathrm{Mg}$ atoms involved in the co-clustering process, and we here have to rely on estimates from a regular solution model.

2 "GPI zones" compete with $\mathrm{Cu}-\mathrm{Mg}$ co-clusters for $\mathrm{Cu}$ atoms and a shift in the relative proportion of the two phases on adding substantial $\mathrm{Mg}$ to $\mathrm{Al}-\mathrm{Cu}$ alloys indicates that the formation enthalpies of the two structures are similar. The enthalpy of formation of "GPI zones" (we could also call them sub nanometer platelets of $\theta$ " $\left(\mathrm{Al}_{3} \mathrm{Cu}\right)$ phase) at temperatures near room temperature has been reported as about $13 \mathrm{~kJ}$ per mol $\mathrm{Cu}$ in the zones $(0.13 \mathrm{eV})$ [23]. This is of similar order of magnitude as the enthalpy of formation for $\mathrm{Cu}-\mathrm{Mg}$ coclusters calculated here, and this comparison provides indication that the enthalpy of formation for $\mathrm{Cu}-\mathrm{Mg}$ co-clusters calculated here must be at least reasonable.
} 
to the $\mathrm{Cu}-\mathrm{Mg}$ co-cluster formation is not unreasonably large. In further support of this we also note that the binding energies between $\mathrm{Al}, \mathrm{Cu}$ and $\mathrm{Mg}$ as used in Monte Carlo simulations [38] provide an enthalpy of formation of $\mathrm{Cu}-\mathrm{Mg}$ bonds that is within $40 \%$ of the value $(\sim 0.27 \mathrm{eV})$ estimated here. Thus, the magnitude of the heat content of the effect ascribed to the $\mathrm{Cu}-\mathrm{Mg}$ co-cluster formation in [2] is fully consistent with our identification of it.

We would note that on the topic of distinguishing clusters from zones on the basis of the magnitude of the calorimetric effect of cluster formation being lower than that of GP(B) zone formation Verlinden and Zahra in the past have written [24]: "Since [calorimetry] is an indirect [technique], the proposed precipitation mechanism cannot directly been (sic) proven but can be used as a working hypothesis that can be confirmed or revoked by other techniques like HR-TEM, APFIM, positron annihilation, etc." We agree with that statement, and would go on to note that for the heat effect of formation of $\mathrm{Cu}-\mathrm{Mg}$ co-clusters our data revoke their suggestions.

\section{Model for reaction kinetics and hardening.}

Zahra et al. [1] questioned the validity of one parameter applied in our reaction kinetics model [2], by suggesting it is unlikely that the cluster formation reaction could occur with $n=2 \frac{1}{2}$. According to applicable transformation theory [39] $n=2 \frac{1}{2}$ will occur for any reaction that is dominated by steady nucleation [40], with few or no nuclei present at the start of the analysis, followed by diffusion-controlled growth [40]. In fact, this agrees very well with our $\chi^{2}$ test on the frequency distribution of $\mathrm{Mg}$ atoms obtained from 3DAP analysis of our alloys which shows that initially, shortly after quenching, the $\mathrm{Mg}$ atoms are distributed nearly perfectly randomly and on roomtemperature ageing the distribution becomes clustered (Fig. 2b in [2]). Correspondingly, no $\mathrm{Cu}-\mathrm{Mg}$ co-clusters are detected in the 3DAP data of samples analysed shortly after quenching and the number density increases steeply on ageing at room temperature (Fig. 4 in [2]). Our data in [2] (for hardness, calorimetry and 3DAP), all obtained on quite thin, water-quenched samples, is clear and consistent.

We would like to add here though that we have recently noted that for our alloys sometimes $\mathrm{n} \sim 2$ provides a better fit to calorimetry data. Actually, this should come as no surprise because from applicable models [41] and relevant data we can determine that $\mathrm{Al}-\mathrm{Cu}-\mathrm{Mg}$ alloy samples will be quench sensitive with respect to the formation of nuclei of $\mathrm{Cu}-\mathrm{Mg}$ co-clusters. For instance, if we consider the models and concepts in [41] combined with the data on the start of formation of nuclei at room temperature in [2] we can estimate that the critical cooling rate needed to fully suppress the start of formation of nuclei of $\mathrm{Cu}-\mathrm{Mg}$ co-clusters is of the order of $10^{2}-10^{3} \mathrm{C} / \mathrm{s}$. For relatively small samples, cooling rates for water quenching below $300{ }^{\circ} \mathrm{C}$ are similar to that rate [42], and hence the ability to fully suppress $\mathrm{Cu}-\mathrm{Mg}$ co-cluster formation during the quench will depend on details of the quenching efficiency. Thus $n$ for $\mathrm{Cu}-\mathrm{Mg}$ co-clusters formation in subsequent experiments will be dependent on details of the quench.

\section{Proposed rationalization of experimental data.}

We believe we can show that, notwithstanding discussions like the present one, the data presented in nearly one century of literature on the subject is consistent. We propose that for early hardening in $\mathrm{Al}-\mathrm{Cu}-\mathrm{Mg}$ based alloys in the $(\alpha+\mathrm{S})$ phase field and $\mathrm{Cu}$ content higher than about 0.3 at $\%$ the 
following sequence of reactions is consistent with all observations. (Note we will avoid using the term "GPB zones".)

i. If the $\mathrm{Al}-\mathrm{Cu}-\mathrm{Mg}$ alloy is quenched sufficiently fast, the $\mathrm{Mg}$ atoms remain randomly distributed [2,3,7] and strength is due mostly to solution strengthening [2]. Some $\mathrm{Cu}$ clustering can occur.

ii. On ageing at low temperature, and providing substantial $\mathrm{Cu}$ and $\mathrm{Mg}$ is available (possibly at least about $0.5 \mathrm{at} \%$ of each element), first $\mathrm{Cu}-\mathrm{Mg}$ co-clusters form and grow. These coclusters do not have internal order. Vacancies are associated with the $\mathrm{Cu}-\mathrm{Mg}$ co-clusters. The rapid hardening is completed when the maximum number density of co-clusters have formed [2]. The structures cannot be detected by diffraction techniques or TEM, but the heat evolution detected by calorimetry is substantial, about $0.3 \mathrm{eV}$ per $\mathrm{Mg}$ atom in the $\mathrm{Cu}-\mathrm{Mg}$ coclusters. If alloying content is very low, $\mathrm{Cu}-\mathrm{Mg}$ co-cluster formation can be by-passed in favour of stage iv or $\mathrm{v}$.

iii. On further artificial ageing (typically 1 to a few hours at 150 to $200^{\circ} \mathrm{C}$ ), ordering will start in the co-clusters, ordering probably is most advanced in the centre of the clusters [19]. The ordering process will tend towards a specific ordering which is probably an $\mathrm{L}_{0}$ type ordering of $\mathrm{Mg}$ and $\mathrm{Cu}$ atoms in the $\mathrm{Al}$ matrix, i.e. alternating layers of $\mathrm{Cu}$ and $\mathrm{Mg}$ [19]. The interfacial energy and strain energy in the now (partially) ordered structure will cause the structure to adopt a rod-like shape. The heat effect due to the ordering reaction is difficult or impossible to detect in DSC because the reaction is relatively slow and because the freeenergy change related to ordering (per alloying atom in clusters) is substantially lower than the free-energy change due to the formation of co-clusters. Some weak evidence of the structures will now start to appear in diffraction techniques and techniques which rely on diffraction contrast (e.g. TEM).

iv. In the next stage the latter structures are replaced by the more stable orthorhombic, space group $\mathrm{Cmmm}$, or the orthorhombic, space group Imm2 rod-shaped precipitate phases $[8,18,19,20]$. These can be imaged by TEM. Around about this stage the strength of the alloys will increase again and $\mathrm{S}$ phase can form on dislocations and other defects that may be present.

v. Full S-phase formation throughout the alloy. S phase forms preferentially on dislocations, and can accommodate slight distortions of its lattice to allow partial coherence with the surrounding Al-rich phase [43].

The relative rates and amounts of phases formed in these reactions will depend on the $\mathrm{Cu}$ and $\mathrm{Mg}$ contents, on the density of vacancies, and on the density of vacancy loops and dislocations which form nucleation sites for $\mathrm{S}$ phase. One important example in engineering applications is that a high dislocation density (for instance in 2024-T3 type material) will cause S-phase formation on dislocations to be strongly enhanced, which can substantially suppress stages iii and iv. The relative amounts of precipitates present at peak ageing condition will thus depend on dislocation content.

We note that each of the structures referred to in i-iv have in one publication or another been referred to as either "GPB" or "GPB2" zones. This is confusing. We propose the following terms better describe our current understanding of these alloys: (small) $\mathrm{Cu}-\mathrm{Mg}$ co-cluster; (partially) ordered co-cluster; the orthorhombic, space group Cmmm, or the orthorhombic, space group Imm2 precipitate phases; $\mathrm{S}$ phase. Each of these can be further defined by reference to shape and 
composition, e.g. rod-shaped partially ordered co-cluster, rod-shaped orthorhombic phase, lathshaped $\mathrm{S}\left(\mathrm{Al}_{2} \mathrm{CuMg}\right)$ phase, etc.

\section{Acknowledgements}

Ms Laury Davin is acknowledged for additional discussions and APFIM analysis.

\section{References}

[1] A.-M. Zahra, C. Zahra and B. Verlinden, Phil Mag Lett. (preceding paper in this issue)

[2] M.J. Starink, N. Gao, L. Davin, J. Yan and A. Cerezo, Phil. Mag. 851395 (2005).

[3] L. Reich, S.P. Ringer and K. Hono, Phil. Mag. Lett. 79639 (1999)

[4] M.J. Starink, N. Gao and J.L. Yan, Mater Sci Eng. A387-389 222 (2004).

[5] S.P. Ringer, K. Hono, T. Sakurai and I.J. Polmear, Scr. Mater. 36517 (1997).

[6] Y. Nagai, M. Murayama, Z. Tang, T. Nonaka, K. Hono and M. Hasegawa, Acta Mater. 49913 (2001).

[7] S.P. Ringer and K. Hono, Mater. Character. 44101 (2000).

[8] S.C. Wang and M.J. Starink, Int Mater Rev. 50193 (2005).

[9] K. Hono, Prog. Mater. Sci. 47621 (2002).

[10] F.W. Gayle and M. Goodway, Science 2661015 (1994).

[11] A. Wilm, Métallurgie 8225 (1911).

[12] P.D. Merica, R.G. Waltenburg and R. Scott, Sci Paper. US Bureau of Standard 15271 (1919).

[13] A. Guinier, Ann. Phys. 12, 161 (1939).

[14] G.C. Preston, Phil. Mag. 26855 (1938).

[15] A. Guinier, Mater Sci Forum 217-222 3 (1996).

[16] Y.A. Bagaryatsky, Dokl Akad SSSR 87397 (1952).

[17] S.P. Ringer, K. Hono, I.J. Polmear and T. Sakurai, Appl. Surf. Sci. 94-95 253 (1996).

[18] S.C. Wang and M.J. Starink, Mater. Sci. Eng. A386 156 (2004).

[19] L. Kovarik, P.I. Gouma, C. Kisielowski, S.A. Court and M.J. Mills, Mater. Sci. Eng. A387-389 326 (2004).

[20] L. Kovarik, P.I. Gouma, C. Kisielowski, S.A. Court and M.J. Mills, Acta Mater. 522509 (2004).

[21] M.J. Starink, Int. Mater. Rev. 49191 (2004).

[22] M. Ohnuma, K. Hono, S. Linderoth, J.S. Pedersen, Y. Yoshizawa and H. Onodera, Acta Mater. 48 $4783(2000)$.

[23] A.-M. Zahra, C.Y. Zahra, K. Raviprasad and I.J. Polmear, Phil. Mag. 842521 (2004).

[24] B. Verlinden and A.-M. Zahra, Mater. Sci. Forum 426-432 423 (2003).

[25] A. Zahra, M. Laffitte, P. Vigier and M. Wintenberger, Mém. Sci. Rev. Mét. 74561 (1977).

[26] Aiwu Zhu, E.A. Starke and G.J. Shiflet, Scr. Mater. 5335 (2005)

[27] L.F. Mondolfo, Aluminium Alloys: Structure and Properties (Butterworths, London-Boston, 1976).

[28] O. Melikhova, J. Kuriplach, J. Ćížek and I. Procházka, Appl. Surf. Sci., In Press (2006).

[29] M.J. Starink, V.M.F. Abeels and P. van Mourik, Mater. Sci. Eng. A163 115 (1993).

[30] M.J. Starink, P. van Mourik and B.M. Korevaar, Metall. Trans. A. 241723 (1993).

[31] T. Sato, S. Hirosawa, K. Hirose and T. Maeguchi, Metall. Trans. A. 342745 (2003).

[32] M.J. Starink and A. Dion, Thermochim. Acta 4175 (2004)

[33] H. Löffler, Structure and Structure Development of Al-Zn Alloys (Akademie Verlag, Berlin, 1995).

[34] C.T. Truong, O. Kabisch, W. Gille and U. Schmidt, Mater. Chem. Phys. 73268 (2002).

[35] A.J. Perry and K.M. Entwistle, J. Inst. Met. 96344 (1968).

[36] K. Peng, W. Chen and K. Qian, Mater. Sci. Eng. A415 53 (2006).

[37] P.C. Bai, T.T. Zhou, P.Y. Liu, Y.G. Zhang and C.Q. Chen, Materials Letters 583084 (2004).

[38] S. Hirosawa, T. Sato, A. Kamio and H. M. Flower, Acta Mater. 481797 (2000)

[39] M.J. Starink, J. Mater. Sci. 364433 (2001).

[40] J.W. Christian, The Theory of Transformation in Metals and Alloys, 2nd ed., Part 1 (Pergamon Press, Oxford, UK, 1975).

[41] P.A. Rometsch, M.J. Starink and P.J. Gregson, Mater. Sci. Eng. A339 255 (2003).

[42] P.A. Rometsch, S.C. Wang, A. Harriss, P.J. Gregson and M.J. Starink, Mater Sci Forum 396-402 655 (2002).

[43] V. Radmilovic, R. Killas, U. Dahmen and G.J. Shiflet. Acta Mater. 473987 (1999). 